\title{
Metodología para el Tratamiento de Riesgos Empresariales
}

RESPONSABLE: Lic. Ramón Mercedes Vera Roalcaba

\begin{abstract}
RESUMEN. El presente trabajo comprende aspectos generales tales como los objetivos, importancia, administración del riesgo en la empresa y el impacto en la rentabilidad de las inversiones; $y$ aspectos especificos tales como la evaluación, valoración, tipo y gestión de riesgos, con una ilustrativa metodología para la gestión de riesgos empresariales, control interno y la gestión de la calidad.
\end{abstract}

MIEMBro: Ing. Edgard Melquiades Pilco Apaza
INTRODUCCIÓN. Gestionar los riesgos eficientemente constituye hoy en día una preocupación de la Alta Gerencia, según afirma Bernens (1997):" la grieta pequeña más grande en la armadura corporativa es la dirección de riesgos". La gestión de riesgos se facilita cuando las entidades desarrollan sus actividades sobre la base de sistemas de control interno acorde con las exigencias actuales. Los sistemas de control interno son una premisa fundamental para que las organizaciones funcionen de tal manera que garanticen el cumplimiento de los objetivos propuestos.

Hoy en día la gestión de riesgos, en el ámbito económico financiero, se inserta dentro de un proceso conocido como Control Interno. El control interno es un concepto universalmente conocido que ha carecido por mucho tiempo de un marco referencial común. Antiguamente los sistemas de control interno se limitaban a las actividades de las áreas de contabilidad y finanzas sin vínculo ni relaciones establecidas, no se consideraba el control interno como un instrumento de gestión capaz de lograr la eficiencia y eficacia de sus operaciones.

Hoy en día la Gestión de Riesgos está presente en casi todas las empresas, incluso las del Estado donde se crean diferentes comisiones o grupos de trabajo para laborar sobre esta temática, proponiendo modelos de control interno que defendian una nueva corriente de pensamiento, con una amplia concepción sobre la organización y una mayor participación de la dirección y del personal en general.

\section{La Importancia de la Gestión de Riesgos}

Un empresario debe saber correr riesgos calculados. No rehúsa los desafios, pero tampoco es un jugador. Evita las situaciones en que el riesgo es muy pequeño,

\begin{abstract}
In the present work is exposed a Methodology for Treatment of business Risks management that understands general aspects such as the objectives, importance, administration of the risk in the company and the impact in the profitability of investments; and specific aspects such as the evaluation, valuation, type and management of risks, with an illustrative methodology for the management of enterprise risks, internal control and quality management.
\end{abstract}

porque no entrañan ningún reto $\mathrm{y}$ no prometen gran cosa. También sabe evitar las situaciones en que el riesgo es excesivo, porque lo que quiere es triunfar. Por lo tanto, evalúa, debe saber evaluar con realismo los riesgos que vale la pena correr.

Ser empresario significa correr riesgos, por lo que debe trabajar bajo la presión de la necesidad de asumir riesgos, debiendo comprender que la posibilidad de un fracaso siempre existe.

"Existe riesgo cuando se tienen dos o más posibilidades entre las cuales optar, sin poder conocer de antemano los resultados a que conducirá cada una. Todo riesgo encierra, pues, la posibilidad de ganar o de perder; cuanto mayor es la posible pérdida, tanto mayor es el riesgo".

Como todo aquel que acepta riesgos, el empresario o directivo deberá tomar decisiones de resultado incierto, evaluando las posibilidades de ganancia en relación con las posibilidades de pérdida. Que se opte finalmente por una alternativa arriesgada o prudente dependerá de: a) los atractivos de cada una; b) su mayor o menor disposición a aceptar la posible pérdida; c) las posibilidades de éxito o fracaso de cada alternativa; y d) el grado en que juzgue factible en cada caso aumentar las probabilidades de éxito y disminuir las probabilidades de fracaso gracias a sus propios esfuerzos.

Lo anteriormente expuesto merece una mayor explicación. Así, cuando hablamos de los atractivo de una propuesta o posibilidad de negocios, debemos analizar qué tan rentable puede ser la misma (ejemplo: rentabilidad de entre un $20 \%$ ó $25 \%$ anual sobre el capital invertido); en cuanto a la disposición a aceptar posibles pérdidas debemos considerar tanto la capacidad psicológica de asumir la misma, pero también 
y vinculada a la anterior, la capacidad patrimonial para afrontarla (ejemplo: no es lo mismo perder $\$ 20.000$ para quien posee una patrimonio de un millón de pesos, que perder el mismo importe para quien posee $\$ 50.000$.-; además no es lo mismo perder en un negocio cuando aparte se poseen otros negocios generadores de utilidades, que perder en el negocio que absorbe todo nuestro patrimonio y dedicación). En relación con las posibilidades de éxito o fracaso de los negocios a encarar, se trata de probabilidades porcentuales, como por ejemplo un $50 \%$ de probabilidades para lograr una rentabilidad de un $20 \%$, o un $5 \%$ de llegar a tener pérdidas ¿De dónde se toman tales datos? Lo mejor es consultar con un consultor que contando con informes estadísticos y experiencia en negocios sepa y pueda guiar al empresario en el análisis del negocio o actividad en cuestión. El cuarto y último punto responde al grado en que el empresario considere que puede adoptar medidas para facilitar la consecución de los objetivos o evitar posibles pérdidas, un claro ejemplo de ello es la persona que dedicada a labores agrarias contrata un seguro contra granizo par evitar pérdidas, o bien pretende asegurar ganancias mediante la venta de su cosecha a futuro. En la medida que los resultados dependan de factores no controlables por el empresario sus posibilidades de éxito disminuirán y se incrementarán sus niveles de riesgos; un claro ejemplo de ello son las actividades de carácter bursátil, sobre todo en países emergentes.

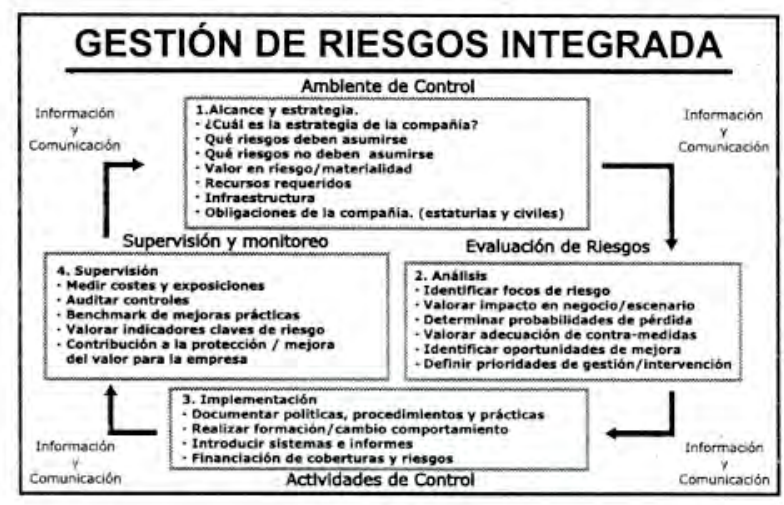

\section{Beneficios de la Administración de Riesgos Empresariales}

Ningún proceso de la administración de riesgos puede crear un ambiente libre de riesgos. Por el contrario la administración de riesgos empresariales permite a la gerencia operar más efectivamente en un ambiente de negocios lleno de riesgos fluctuantes.

La administración de riesgo empresarial proporciona capacidad aumentada para:

- Alinear el riesgo aceptado y la estrategia: En su evaluación de alternativas estratégicas, la dirección considera el riesgo aceptado de la entidad en la evaluación de alternativas estratégicas, estableciendo los objetivos relacionados y desarrollando mecanismos para administrar los riesgos asociados.
- Reducir las sorpresas y pérdidas operativas: Las entidades consiguen mejorar su capacidad para identificar los eventos potenciales y establecer respuestas, reduciendo las sorpresas y los costos o pérdidas asociados.

- Mejorar las decisiones de respuesta a los riesgos: La administración de riesgos corporativos proporciona el rigor para identificar y seleccionar entre las posibles alternativas de respuesta a los riesgos: evitar, reducir, compartir y aceptar.

- Recursos: Una clara comprensión de los riesgos que enfrenta un negocio puede hacer más efectiva la dirección, la administración del tiempo y de los recursos del negocio para manejar riesgos.

- Identificar y manejar los riesgos cruzados de la empresa: Cada negocio hace frente a innumerables riesgos que afectan diversas partes de la organización. Los beneficios de la administración de riesgos empresariales solamente se optimizan cuando se adopta un enfoque integral de la empresa, integrando las diferentes perspectivas a la administración de riesgos dentro de una compañía. $\mathrm{La}$ integración tiene que ser efectuada de tres maneras: centralizar los reportes del riesgo, la integración de las estrategias de la transferencia del riesgo y la integración de la administración de riesgos en los procesos organizacionales de una empresa. En lugar de ser un mecanismo puramente defensivo, puede ser utilizado como un instrumento para maximizar las oportunidades.

- Ligar el crecimiento, el riesgo y rendimiento: Los negocios aceptan riesgo como parte de la creación de riqueza y su sobrevivencia, y ellos esperan un rendimiento que compense el riesgo. La administración de riesgos empresariales proporciona una mayor capacidad de identificar y de evaluar riesgos, y de establecer niveles aceptables del riesgo en relación con el potencial de crecimiento y el logro de objetivos.

- Racionalizar el capital: Una información más sólida sobre la exposición del riesgo permite a la gerencia evaluar más efectivamente las necesidades de capital y mejora la asignación del capital.

- Aprovechar las oportunidades: Mediante la consideración de una amplia gama de potenciales eventos, la dirección está en posición de identificar y aprovechar las oportunidades de modo proactivo.Hay tres principales beneficios de la administración de riesgos empresariales: mejora el funcionamiento del negocio, incrementa la efectividad organizacional y logra mejores reportes del riesgo. 


\section{Marco de la Administración de Riesgos Empresariales}

El marco para entender la administración de riesgos empresariales se incluye en la figura y se compone de cinco elementos.

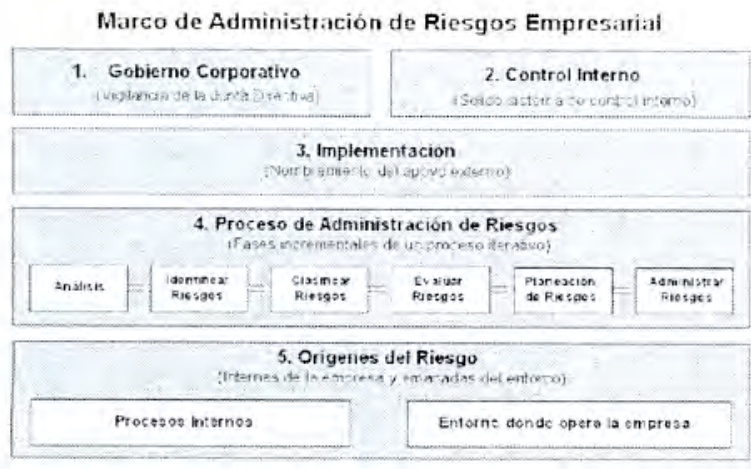

1. El gobierno corporativo se requiere para asegurarse de que la junta directiva y la gerencia hayan establecido los procesos organizacionales apropiados y los controles corporativos para medir y para manejar los riesgos a través de la empresa.

2. La creación y el mantenimiento de un sistema sólido de control interno se requiere para salvaguardar la inversión del accionista y los activos de la empresa.

3. Un recurso específico se debe identificar para implementar los controles internos con suficiente conocimiento y experiencia que genere el máximo beneficio del proceso.

4. Se requiere un claro proceso de administración de riesgos que establezca los procesos individuales, sus aportaciones, sus resultados, sus limitantes y sus responsables.

5. El valor de un proceso de administración de riesgos se reduce sin una clara comprensión de los orígenes del riesgo y a cómo deben ser respondidos. El marco separa los orígenes del riesgo en dos elementos clave, denominándolos procesos internos y el entorno donde opera la empresa.

\section{METODOLOGÍA PARA LA GESTIÓN DE RIESGOS EMPRESARIALES}

La administración de riesgos es reconocida como una parte integral de las buenas prácticas gerenciales. Es un proceso iteractivo que consta de pasos, los cuales, cuando son ejecutados en secuencia, posibilitan una mejora continua en el proceso de toma de decisiones. La administración de riesgos es un término aplicado a un método lógico y sistemático de establecer el contexto, identificar, analizar, evaluar, tratar, monitorear y comunicar los riesgos asociados con una actividad, función o proceso de una forma que permita a las organizaciones minimizar pérdidas y maximizar oportunidades. Puede ser aplicado a todas las etapas de la vida de una actividad, función, proyecto, o producto. (Arce, 2005)

Entre los expertos en la materia de administración de riesgos no hay unanimidad en la segmentación del proceso, aparece definido en diferentes fases, pero si existe coincidencia en los aspectos claves de dicho proceso que abarca una fase predominantemente cognoscitiva que podría denominarse fase del estudio, otra de carácter práctico, la fase de la implementación y la tercera - la fase de control y la comunicación. En la primera se realizan: la identificación, el análisis y la evaluación de los riesgos. En la segunda se implementa el plan de la respuesta a los riesgos. La tercera fase esta formada por las actividades de monitoreo, control y comunicación (Koprinarov,2005).

Por su parte la norma AS/NZS 4360:1999 aunque de manera general coincide con los aspectos presentados por la Resolución 297/03, hace énfasis en la necesidad de concebir un modelo para el análisis de los riesgos sustentado en los requisitos de los sistemas de gestión de la calidad expuestos por las normas de la familia ISO 9000 .

EI Servicio Nacional de Aprendizaje SENA (2004) fija las políticas en materia de administración de riesgos en la Resolución No. 01975 donde propone una metodología de once pasos fundamentales estableciendo como un aspecto fundamental la inclusión de indicadores de efectividad de las acciones propuestas, no contemplado en metodología anteriores.

Especialistas como DMR-Consulting (2005) proponen un método llamado Administración del Riesgo Operacional (ARO), cuyo objetivo principal es operativizar una metodología de trabajo, incorporando los indicadores necesarios. Además propone:

- Identificar el riesgo, clasificar e incorporar en la base de datos.

- Buscar causas.

- Proponer medidas de cambio con base en la gestión de procesos

- Realizar seguimiento.

Pinkerton Consulting and Investigations, empresa consultora inglesa y una de las más grandes del mundo, propone como metodología para la gestión de riesgos los requisitos del Informe Tumbull (CSJ, 1999), que se resumen en el siguiente cuestionario:

- ¿Es su empresa plenamente consciente de los riesgos de la organización, y éstos se valoran, comunican y entienden claramente?

- ¿Tiene su empresa una estructura organizativa que propicie una gestión eficaz y una mitigación de los riesgos?

- ¿Existe una identificación de los riesgos derivados de la adquisición de la empresa por parte de directivos ajenos a la misma y un control a todos los niveles de su empresa? 
- ¿Es el sistema de valoración de riesgos de su empresa transparente de modo que permita a los accionistas estimar el riesgo?

- ¿Se considera que la valoración de riesgos es una tarea independiente o está incluida en la actividad de su empresa?

Los requisitos básicos del Informe Turnbull son:

- La junta directiva debe mantener un sistema sólido de control interno.

- Un miembro de la junta deberá realizar una revisión de la eficacia del sistema de control interno de la empresa con una periodicidad mínima anual. La revisión anual tiene que abarcar todo tipo de controles, incluyendo control financiero, operativo, y de conformidad y gestión de riesgos.

- Los miembros de la junta directiva deberán informar a los accionistas de que se ha realizado dicha revisión-normalmente, en el informe financiero y en las cuentas anuales.

La FAO aplica un sistema que internacionalmente ha tenido un gran impacto por el enfoque utilizado para la gestión de los riesgos, que es el sistema de Análisis de Peligros y Puntos Críticos de Control (APPCC), utilizado para la prevención de la seguridad de alimentos ( FAO, 2002). A partir de los resultados prácticos referidos de su aplicación en la industria alimentaria, este sistema se ha venido utilizando y se ha convertido en una práctica aceptada en otros sectores productivos y de servicios, con excelentes resultados (Rooney, 2001; Ambrustery, 2001).

Como sucede con la mayoría de los sistemas o metodologías para la organización de una actividad, dígase sistemas de gestión de la calidad, sistemas de APPCC, metodología para la mejora continua, entre otros, donde existen regulaciones, normas $\mathrm{u}$ otras disposiciones generales que establecen las pautas más importantes e imposibles de obviar, cada entidad debe establecer sus propios sistemas y métodos como "trajes a la medida" identificando y teniendo en cuenta sus características propias.

\section{MATERIAL Y MÉTODOS UTILIZADOS}

\section{Material Utilizado}

- Internet

- Biblioteca

- Normatividad del Estado peruano

- Libros y revistas afines

\section{TÉCNICAS Y MÉTODOS DE TRABAJO}

- Sesiones de trabajo diarias

- Discusión y prueba de la información obtenida.

\section{PROCESAMIENTO YANÁLISIS DE DATOS}

Recolección de los datos acerca de las operaciones a realizar

\section{CONCLUSIONES}

1.El Tratamiento de Riesgos Empresariales de una Organización permite dar una seguridad razonable de la empresa en el tiempo ante una amenaza.

2.Dependiendo del tamaño de la institución u organización se deberá dar tratamiento a los riesgos Empresariales previo análisis costo/beneficio.

\section{RECOMENDACIONES}

1. La aplicación costo/beneficio debe ser evaluada técnicamente para el tratamiento de los riesgos.

2. Involucrar a los usuarios en la detección de los riesgos de la empresa

\section{REFERENCIAS BIBLIOGRAFÍA}

DOMINGUEZ MACHUCA, J.A. DURBÁN OLIVA, S. y Martín Armario, E. (1987): "EL SUBSISTEMA DE INVERSIÓN Y FINANCIACIÓN DE LAEMPRESA". Editorial PIRÁMIDE.

DURBÁN OLIVA, Salvador. INTRODUCCIÓN A LAS FINANZAS EMPRESARIALES. Editorial UNIVERSIDAD DE SEVILLA.

DURBÁN OLIVA, Salvador. LA EMPRESAANTE EL RIESGO, Editorial HISPANOEUROPEA DE EDICIONES.

ARCE, M. Documentación para la administración de riesgos. Grupo Kaisen,S.A.

BACA, A. "La Administración de Riesgos Financieros". Revista Ejecutivos de Finanzas, publicación mensual, No.11, México, 1997. 